\title{
THE IMPORTANCE OF MANAGEMENT AND LEADERSHIP IN A CHANGING BUSINESS ENVIRONMENT
}

\author{
Roxana Mironescu \\ "Vasile Alecsandri” University of Bacau \\ roxy_mironescu58@yahoo.com
}

\begin{abstract}
Change is a factor of impact on managerial functions especially upon those related to the coordination and training of the human resources. Change management is a broad spectrum of means, referring to different types of change, however, it is generally used in the processing management and in the strategic management, in the information management, including the electronic one. The analysis of changes inside the organization is very important, these changes allow the organizations to be more adaptable and innovative. However, some changes may suddenly occur and will independently act of the managers'will. If we are talking about the human change, then we should mention that the importance of this dimension of the organizational change is essential. The way people relate to change can be affected by the position they occupy inside the organization and the attitudes they adopt facing the change influence the role that they assume with the greatest ease in the change processes. Leadership and the organizational culture are in a tight relationship. Manager evaluates its business, in addition to a number of work processes and products, and the cultural environment too, so conducive, in his view, that it should activate and record the organizational and work performance.
\end{abstract}

\section{Keywords}

change; resistance to change; performance; managers; leaders; change management

\section{JEL classification}

M10

\section{Introduction}

Most experts consider the management to be an economic field of synthesis, but in the recent decades due to its deeper and deeper implication in some located beyond the limits of economics fields of activity, make it intersect with cultural decision within transnational corporations where the organizational culture differently evolves face to the country of origin or in certain cultural institution, as a production unit, specialized in aesthetic values or in their dissemination.

The symbiosis between culture and management is appropriate and beneficial , the two fields influencing each other. Some of the most significant consequences of the culture on the management processes may be: providing the general background for the applicability of management, managerial creativity enhancing, optimizing the decision-making process of forecasting and consulting, identifying and capitalizing on opportunities arising from the external environment.

In a complementary process, the infusion of the scientific management in the institutions of culture and education, hospitals or public administration may lead to ensure an efficient organizational climate to boost the overall cultural phenomenon, to a more judicious allocation of the resources, which are already poor in the mentioned fields of activity. In this context, the importance of trained and dedicated leadership and the management knowledge they possess, becomes as a maximum significant criterion for any present organization. 


\section{Conceptual approaches}

According to the modern approaches, managers are primarily administrators: make-up business plans, analyze and establish budgets, control the way the work tasks are fulfilled and the development program parameters. Administrator status is opposite to the employees' wishes who do not want to be managed, but to be led. On the other hand, leaders determine the change inside the organizations and also at the human individuals level. Between management and leadership there is a subtle difference: if management is a necessary function of any organization or business, leadership establishes a relationship between the leader and the led, which can stimulate the smooth running of the activities of the organization. Effective management involves the daily monitoring and achievement of the business objectives, solving problems in the proper time, the management of the departments within the limits imposed by their budgets, work meetings, negotiations. Leadership has a business perspective, it creates ideas , motivates employees and becomes imperative when changes in internal or external environment threatens the stability of the organization. Thus, management can be considered an executive function (planning, conceiving budgets, evaluates, mediates), while leadership is a special type of interpersonal relationship (selects values, motivates, coaches, build like ideal models or typologies). An American specialist appreciates that management is based on a large amount of scientific information ("80\% science") and only on a small part of inspiration and creativity ("20\% art"), while leadership is based on its opposite (" only $80 \%$ art and $20 \%$ science") . Leadership can be studied, it can be improved, but one cannot ignore the innate qualities of the people involved in this process. Folk wisdom says: "champions do not become champions in the ring, they just get there the recognition". The success is assured by the talent, completed with training, practice, perseverance and continuous development, therefore, leadership is not an option, it can not be delegated or obtained by someone through the acquired titles. The leader is that respected person by those around her, that willingly followed person, the individual whom to trust, beyond the conferred by the title of the position held or the exercised authority. The history is full with examples of leaders, exceptional people, who appear, sometimes, out of nowhere, which solves certain desperate situations or obtain impossible victories. They correspond to the human need to have heroes, to look at the positive patterns of behavior, they derive from the people's desire to be dependent on an authentic ruler.

Beyond these psychological considerations, the need for true leaders is an important topic of the present moment in the Romanian economy and society. The organizations of today are tightly managed, as a rigid response to the turbulent conditions existing in the external business environment. It should be an ideal situation where the manager can determine his employees to follow him by their own will. The reality is, however, a little different: managers force their employees to leave their comfort zone, so they turn either rebels or become bored and unmotivated. Another real argument that pleads against leadership is the managers, no matter how competent they are stagnant, restricted because of the limitations in achieving urgent immediate tasks and objectives. Management and leadership complement each other, the success accomplished in one of the positions, however, does not guarantee the success in the complementary position. There are no known methods to train and to grow strong leaders. The training, including the practice in Romania, focusses on the people training to solve everyday practical problems. In this way, it inhibits the development of a leadership scale. At the same time, the presence of a leader with a strong personality make an opposition to a manager development, as a confrontation between pragmatism and disorder, between mechanistic and inspiration.

Encouraging the creation and training of the leaders is one of the fundamental problems of post- revolutionary Romanian economy, marked by strong changes. 
Leadership is a complex activity. Some management experts focuss their efforts upon developing native personality of the leaders, others focuss upon the development of a management team or upon the management by objectives.

Anyway, the manager must be able to lead a group of individuals, but also to be able to adopt a different style of leadership based on the team entities' personalities. The effectiveness of leadership consists of a mix of traits, such as intelligence, selfconfidence, initiative, excellent communication, the ability to abstract and generalize situations and events, the ability to correctly perceive the essence of the different phenomena. Generally speaking, " to be a leader" is synonymous with "to set an example" to follow, because the subordinate individuals are tempted to follow, step by step, that personality considered to be a model of professionalism and existence. In the 60s and 70s, researchers formulated two major coordinates of the leadership behavior, based on the managerial behavior, explained by the model-grid Blake or on the three-dimensional managerial behavior model (3-D) Reddin:

- Leader acts to achieve initial control tasks, to encourage the employee in accepting the minimum level of performance of such tasks ;

- Once reaching this minimum level of performance, the manager rewards performance through an emphasis on human relationships by providing the human resources attention, support and direct encouragement. With the maturation of the assumption of the tasks and of the enhance the work performance, the manager increasingly offers more autonomy by delegation and trust.

This management model is dynamic, it provides a guide to different behavior, both for the diversity of employees' personalities and for the complex levels liable for the fulfillment of work tasks.

Quoting Fred Fielder:" the best description of a perfect leader would be that character, who use intuition or training, know how to control the proper environment"; and we could add "effective control proper environment", according to the management style and to the best leadership methods, related to his own personality. Even if managers and leaders are different human types, they have nuanced attitudes face to goals, career, relationships with the others and with themselves, in such spectacular changes we live and work in, a fusion of the two philosophies of the rulers may be not only necessary but also feasible and perfect.

The leader is called to intensify a whole mechanism of interests, hopes, motivations and organizational energies in an unique amazing direction, to differentiate from other similar organizations, but also to obtain the long awaited benefits. The managerial vision of the organization, originally designed by its leader, will live step by step, as an integrator and an accelerator of a fully participative climate predisposed to great performance due to the manager's pragmatism and the the leader's inspiration.

A technicist leader type will particularly ensure the effectiveness of the organizational activities by the specific approach of his mission, the charismatic leader will prove to be a crucial factor in stimulating the creative energies in challenging undertaking commitments. The two patterns of a leader can be combined, by original methods, according to the management style, taking into account the features and the abilities of each implicated individual. Despite all the difficulties of each typology of leadership (the lack of a precise definition of the institutional organizational framework, in the practice of the control, certain deficiencies to achieve a real participative management etc.), experienced and talented managers will always be able to require nuanced behaviors, developing harmoniously in both senses of the leadership.

Lewin since 1951 suggests that any change or innovation can be understood through three successive stages: freezing, changing or moving (turning) and refreezing. Lewin believes that organizations are essentially stable structures, and the change is the 
process where the organizations move between different stable stages. The model has been criticized for "a static vision of the organization". Lippit (Renewal Organization, 1982) cites the organizational crisis phases, such as: shock, defensive awareness, adaptation and change. Elizabeth Kubler -Ross (1970) establishes similarities between the managerial model of the change management and people's reactions when they are sick, unexpectedly informed of an incurable illness: denial, rebellion, bargaining, depression and finally acceptance.

The manager/leader may be interested in either performance of the change made by a person or in the average performance over a group of people. If an individual is the target of change the changing effort requires can be different from that the effort needed for collective change. In an attempt to change the behavior of a person is necessary to know certain details about that individual, and the plan for change must be adapted according to his needs, values, background and interests. If the target change but the performance is aiming the group (daily results in the activity, the presence at the work place, absence rates and abandoning employment income), the strategy is oriented towards collective change of a significant number of people

A large number of people and organizations face with the appearance of the collective change versus the individual change. For example, the officials in charge of traffic safety are concerned with the rate of accidents and deaths around the holidays. At the same time, these people are concerned that their own children to be safe .The change strategies, individually or collectively applied, are always tailored to the men. When a change occur, this is due to the fact that the people's performance is declined. Sometimes people speak and write as if "organization” is a tangible entity, different from the people who compose it. In this respect, it is common expression " the organization has suffered a decrease in sales or production”. But the organization is an abstraction - organizations do not change in their behavior, although a change in the structure of the organization or its processes can impact on the organizational behavior. In fact, what it appears is a group of people who share consciously or unconsciously the same common guidelines and decide to change their behavior. A strategy to produce change is always oriented towards influencing the human behavior.

\section{Change management and the manager's/leader's role in changing}

Change management refers to the adoption of such mutations in a planned, structured and organized environment. The most important topic of the change management is a set of questions such as: how do we make the organization more innovative, more competitive and more productive? What are the required changes? What are the performances measures us trying to adopt? Why do people feel the need to be more creative? An important question concerning the organizational change is "Why the organizations change?" And the answer can be, as follows:

- Because of the poor performance they have;

- $\quad$ To adapt to the changes form the external environment;

- To achieve or to maintain a competitive advantage (such as better prices, high quality) compared to the market competitors;

- $\quad$ To put into practice an innovation.

Organizational change can be continuous (progressive developments, accurate adjustments, incremental adaptations) or discontinuous (rupture or radical changes), depending on the evolution of the environment. People do not engage in the changing behavior than when faced with a need for change. This need is felt like an emotional discomfort that decreases as the need is satisfied. One of the important change occurs when a manager feels the need to improve the results, the but subordinates do not have the same need. In the past, managers have tried to make people feel the need to 
change trying to create feelings of fear, guilt, crisis or the complex of reward punishment. When these forces are set in motion, the need is to cope with the induced conditions, but not to change behavior in order to improve performance.

It's easy to generate a need for change in the terms of the managerial targets:

1) provide clear and accurate information about the need for change;

2) allow the others to engage in planning change;

3) allows people to experience a form of reward for their involvement in the change.

We can also say that two sources are determining the organizational change:

- the External sources - the change is initiated or imposed by actors and interest groups outside the organization;

- the Internal sources - the change starts with individuals and groups such as shareholders, managers, employees.

Another fundamental question concerning the subject of the change might be: "What it can changed inside the organizations?" The most frequent changes are:

- $\quad$ the Objectives and strategies;

- $\quad$ the Technologies;

- $\quad$ the Human Resources;

- $\quad$ The Organizational structures;

- $\quad$ The Environment.

Kurt Lewin believes that change is a work in a dynamic equilibrium, where various forces are pushing to amend the parameters consecrated inside the organization, but at the same time, they provide a strong resistance to any change of the system, treated as a whole or in its components. Among the most important determinants of the organizational change, it could be taken into consideration: the technological change, the high rate of obsolescence of the products, the improved working conditions, and the avalanche of the new information. And the resistance to change is induced by many factors, such as: the outdated attitudes, the individual or collective mental patterns of acting or thinking, disinterest, the fear facing of the unknown and the new, the fear of a possible failure, a low degree of professionalism, the destructurated labor forces.

Defining a work team as a group of people working independently to achieve common objectives, where its members are responsible for the accomplishment of the objectives, we can conclude that, through certain collective effort, teams can pass over the sum of the individual performance and over their members' private objectives. Effective teams develop useful mechanisms to maximize their performance. We list some features of building a work team, as follows:

- $\quad$ team members must share a sense of power;

- $\quad$ they have a high score of selfconfidence;

- $\quad$ team members show superior motivation and a volitional attitude.

In terms of communication within a team of high potency, their members were close to each other during a conversation, a meeting or an interview; they supported one another in argumentation and talked about their successes with pride.

In terms of communication within a team of high potency, their members were close to each other during a conversation, a meeting or an interview; they supported one another in argumentation and talked about their successes with pride. The members of a team that lacks a shared sense of power embarrassed smile when they are asked about their achievements, they are scattered throughout the room, often contradict each other, related to a particular topic. In the teams with a deep sense of solidarity, their members talk about "we" and "us", while in the teams with low cohesion it is about "me", "I" facing to "them".

Concerning the autonomy in the work teams, it refers to the freedom, the discretion and the control their members can give evidence and can experience. Performing 
teams are free to use their resources to exploit the opportunities and take quick decisions without needing the superviser's or a chief's approval.

These teams have the discretion of the major decisions, the so-called "sense of impact" that occurs when the team efforts converge and have a positive impact on the stakeholders' interests. Today the Human Resources managers develop the "sense of the impact" beyond the simple verbal statements, but in certain concrete ways, accordingly with profitable and flexible plans. The reactions from the internal and external clients help to strengthen the "sense of the impact".

What is really needed in order to achieve a strengthened team and to increase its effectiveness? First of all, it is necessary, but not sufficient, that each member has his proper management, the team autonomy, as one of the four dimensions of the team cohesion. Many studies have revealed the importance of the autonomy, as an unique factor, to enhance and to strengthen the work teams. When the management style, the production and service systems, the social structures, the organizational and Human Resource policies and all together create major obstacles to the effectiveness of work teams, even those welded, with a strong group cohesion, will have major difficulties to handle the corporate twists.

When a leader is expressing considerations, such as: "nothing is not really changed here, the workers are the same obsolete people, we are doing the same old procedures, only the name is different" it means that the company has implemented a very narrow version of a teamwork, without a broad vision on the organizational context.

Other studies suggest that we can not expect managers to suddenly act totally different, just because they were told and they were forced to work in an organization based on the teamwork. Those companies able to invest in education and lifelong learning are most likely to receive the benefits of the consolidated teams. Inside those companies, the performing leaders benefit from a period of training or mentoring with the purpose of facilitating their function, before being appointed to managerial positions, this practice could be translated by "everyone in the company $\mathrm{X}$ can be the leader and is waited to be a leader in a certain perspective of time or "I will never ask anyone to do what I could never ever do".

Other organizational aspects consist in the change occurred in the operational systems, which must be accompanied by corresponding changes in the control system to achieve the success of an intervention in order to strengthen group cohesion.

Other research indicates that people will start to change if the need is felt by a respected and important person. It is not unusual for people to adopt behavior change by themselves. This is especially true regarding the organizational behavior. If the employees know that certain important people inside the organization supports the idea of change, they are not averse to the idea.

Yet even after the start of changing behavior it is necessary to continue the needed change. One can talk about a model of change, about resistance to change and about how you can prevent this resistance. The context of change is the situation in which necessary to cause a change in the organization. No matter what kind of change is about the process tends to enroll in a pattern. Management must recognize that change is needed, a proper method should be identified and applied for changing and leaders/managers are called and have the choice to find a proper method to produce change.

\section{Conclusions.}

The topic of change is a dimension of content, but also another dimension, that of processing. Therefore, there are at least three emerging theoretical and methodological approaches of change management: managing it in a reactive or in a proactive sense, the existence of certain expertise and professional practice areas 
(with the practitioners' in changing dependent variable level of skills and abilities) and consecration of some methodological tools, consisting of patterns, techniques, methods and other tools, able to reveal the true causes, the effects and the ways to maintain a favorable climate inside the change processes. To properly work, the manager must be familiar with the critical situation, involving the change. A stage which involves the diagnosis of the current situation becomes imminent. In our country, the problem of the interaction between management and leadership is particularly acute, starting from the required definition of these two concepts, to the different structures and qualities of the categories in question. In the decades of application of the socialist organization principles in the Romanian economy and society, it has been proliferated a deliberate and natural selection, promoting a human typology of manager, such as the obedient bureaucrat, the demagogue, the duplicitous, lacking strong culture, the false authoritarian and the dishonest one. Certain qualities such as initiative, responsibility, independence, original way of perceiving reality were declaratively stated, but at the same time, there were classified as "reactionary," "imperialistics". Unfortunately, those bad fundamentals characteristics mentioned above have been maintained since 1990, till now, entire generations of men, invested with the status of managers were and are still marked by this poor philosophy. Current socio-economic configuration has led to the existence of two types of leaders, both as less competitive: the bureaucratic manager and the business entrepreneur type.

We believe that Human Resources management policies are likely to increase solidarity within work teams; therefore, it is necessary that managers and leaders assume clear responsibilities in this area. In many organizations these kind of decisions have been delegated to the Human Resources team. Often, the teams analyze and select the new members of the organizations. About the integration of newcomers, the work teams take responsibility for their guidance in terms of regulations and rules, it entrusts with its own procedures for assessing achievement of the individual performance, applying rewards or sanctions, as appropriate, for the disobedient workers. The members in certain sales team have also developed processes to performance evaluation; taking into account the customer feedback and the specific content for their performance evaluation are equally treated.

There are many models of organizational change process stages, but one of the best known is that of

\section{References}

Bennis, W., Benne K.D., Holt, R. C. (1969), The Planning of Change, Rinehart and Winston, New York.

Change Management [Wiki], available on http://en.wikipedia.org./wiki/Change Management.

CODECS (2002), Putere, conducere şi schimbare, Managementul schimbării.

Mandru, B., Adaptarea instituţională si Managementul Schimbării, available on http://bogdanmandru.wordpress.com/management-organizationalmanagementul-schimbarii-in-organizatii/.

Scullion, H., Linehan, M. (2005), International Human Resources Management, Palgrave Mac Millan, New York.

Tompkins, P.K. (1987), Translating organizational Theory: Symbolism over substance, Beverly Hills, CA Sage.

Zecheru, V.(2001), Management în cultură, Ministerul Culturii şi Cultelor, Centrul pentru formare, educaţie permanentă şi management în domeniul culturii, Bucureşti, România. 